\title{
HISTÓRIA DA EDUCAÇÃO PRIMÁRIA: INSTITUIÇÕES E ORGANIZAÇÃO DO TRABALHO ESCOLAR (1950-1960)
}

\author{
History of Primary Education: institutions and organisation of school work (1950- \\ 1960)
} Historia de la Educación Primaria: instituciones y organización del trabajo escolar
$(1950-1960)$

\author{
Ednéia Regina Rossi* \\ Jordana Ferreira de Faria**
}

\begin{abstract}
Resumo
Neste artigo, o objetivo é evidenciar como se expandiu o ensino primário público no Brasil e, particularmente, no Paraná, nas décadas de 1950 e 1960. Para o trato das fontes, adotou-se o método de análise de conteúdo. Na interpretação, conceitos teóricos propostos por Certeau (1998) e Chartier (1990) permitiram identificar formas originais na configuração do uso ou aplicação de modernos conhecimentos educacionais à realidade brasileira. Assim, no interior paranaense brasileiro, configurou-se um modelo de organização de escola que conjugou muitas das novidades do campo educacional às condições de um país agrário, de proporções continentais, com escassez de recursos e de qualificação profissional.
\end{abstract}

PALAVRAS-CHAVE: História da Educação Primária. Instituições escolares. Organização do trabalho escolar.

\begin{abstract}
This article aims at showing how elementary schooling expanded in Brazil, particularly in the state of Paraná, in the 1950s and 1960s. For the handling of the sources we adopted content analysis. In the interpretation, theoretical concepts proposed by Certeau (1998) and Chartier (1990) made it possible to identify original forms of configuration in the use or application of modern educational knowledge tailored to Brazilian reality. Thereby, in the countryside of Paraná State, a model of school organization combined many of the innovations of the educational field with the conditions of an agrarian country of continental proportions, with scarce resources and little professional qualification.
\end{abstract}

\footnotetext{
* Professora Associada da Universidade Estadual de Maringá. (UEM). Graduada em Pedagogia pela Universidade Estadual de Maringá (UEM). Mestre em Educação pela Universidade Estadual de Maringá (UEM). Doutora em História pela Universidade Estadual Paulista Júlio de Mesquita Filho (UNESP). Líder do Grupo de Pesquisa em História da Educação Brasileira, Instituições e Cultura Escolar (HEDUCULTES). Pesquisadora visitante na Universidade de Genebra /Suíça (2019-2020). Endereço: Universidade Estadual de Maringá, Centro de Ciências Humanas Letras e Artes, Departamento de Fundamentos da Educação, Av. Colombo, 5790 Zona 0787020900 - Maringá, PR - Brasil. Telefone: (044) 3011-4839. E-mail: errossi@uem.br. Orcid: https://orcid.org/0000-0002-7551-5397

** Mestre pelo Programa de Pós-Graduação em Educação da Universidade Estadual de Maringá (UEM). Professora na Educação Básica. Endereço: Colégio São Domingos, rua dos Dominicanos, no 471 Centro 86840000 - Faxinal, PR - Brasil. Telefone: (43) 34611346. E-mail: fariaJfaria22@gmail.com. Orcid: https://orcid.org/0000-0002-6089-2560
} 
KEYWORDS: History of Elementary School. Schooling institutions. Organisation of school work.

\section{Resumen}

Este artículo pretende mostrar cómo se expandió la educación primaria pública en el Brasil y en particular en el Paraná en las décadas de 1950 y 1960. Para el tratamiento de las fuentes se adoptó el método de análisis de contenido. En la interpretación, los conceptos teóricos propuestos por Certeau (1998) y Chartier (1990) permitieron identificar formas originales de configurar el uso o la aplicación del conocimiento educativo moderno a la realidad brasileña. Así, en el interior de Paraná, en Brasil, se configuró un modelo de organización escolar que combinaba muchas de las novedades en el campo educativo con las condiciones de un país agrario, de proporciones continentales, con escasez de recursos y de calificación profesional.

PALABRAS CLAVE: Historia de la Educación Primaria. Instituciones educativas. Organización del trabajo escolar.

\section{INTRODUÇÃOO}

A escola pública, gratuita e estendida a todas as crianças, coloca-se como a maior preocupação dos governos republicanos brasileiros desde o final do século XIX e grande parte do século XX. A expansão do ensino primário ocorreu com a sua institucionalização, ou seja, com a criação de espaços próprios de ensinar, tornando-se condição inquestionável para sua realização. Ao se institucionalizar, o ensino assume a forma escolar, nos dizeres de Guy Vicent (2001), com suas prescrições e práticas, constituindo uma cultura que lhe é própria.

Analisamos, neste artigo, as circunstâncias em que, no Brasil e no Estado do Paraná, a escola isolada significou a possibilidade de expansão de vagas públicas e a extensão do ensino primário ao maior número de crianças, na luta contra o analfabetismo no Brasil.

Várias razões sustentariam esta luta. Para Bittar e Bittar (2012), a democratização do ensino ganharia força a partir de 1930, com o projeto de desenvolvimento econômico, por meio da industrialização. A ideia de desenvolvimento e modernização impulsionaria os ideais de uma escola pública destinada a todos. Para Bobbio (2004), a democratização da educação, ao longo do século XX, estaria relacionada com a Declaração Universal dos Direitos Humanos, proclamada em 1948, que apregoa que todo sujeito teria direito à educação e que ela deveria ser gratuita e obrigatória, não menos que nos graus elementares e fundamentais. Assim, a educação possuía uma utilidade, quer na constituição de um quadro de sujeitos com melhor capacitação para o trabalho, quer por favorecer certa inserção e participação social dos sujeitos.

Como fonte de análise, foram utilizados dados estatísticos, mensagens de governadores e entrevistas realizadas com ex-professores de escolas isoladas. Metodologicamente, o caminho adotado foi o de leitura exaustiva das fontes, realizando a codificação e classificação do material e, posteriormente, a categorização de seu conteúdo. Para discussão dos dados, foram feitas interpretações tendo por base estudos historiográficos e conceitos teóricos. O conceito de bricolagem, proposto por Michel de Certeau (1998), possibilita interpretar que os sujeitos se apropriam de modelos, ideias, cultura, e os reorganiza, com autonomia e insubmissão, criando e recriando novas formas. Da mesma maneira, Chartier convida a reconhecer que as objetivações 
constroem formas originais toda vez que se configura o uso de determinada coisa, sendo imperioso escrever uma história dos usos e representações (CHARTIER, 1990).

Partimos do entendimento de que a organização do trabalho escolar da escola pública se constrói sob premissas de consenso em uma temporalidade e lugar. Os tipos de instituições escolares existentes assumiram características particulares, a depender do lugar em que se inseriram. A escola isolada de meados do século XX esteve alinhada aos elementos definidores do modelo escolar graduado de organização.

\section{Escolarizar a todos: o contexto populacional das décadas de 1950-1970 do século}

\section{XX}

A educação básica brasileira, ao longo de todo o período republicano, teve desafios imperiosos. No período em questão, o combate ao analfabetismo mobilizava educadores, políticos e grande parcela da sociedade civil. Comecemos a dimensionar os contornos desse desafio, analisando a distribuição demográfica e a movimentação da população pelo território brasileiro. Se, até $1950,63,84 \%$ da população vivia em zonas rurais, enquanto $36,16 \%$ vivia em zonas urbanas, a partir de 1970 , a concentração da população que vivia em zonas rurais era de 44,02\% e, na zona urbana, chegava a $55,98 \%$. Observemos a tabela abaixo.

Tabela 1: Residentes no Brasil nos anos de 1950, 1960 e 1970 - área urbana e rural

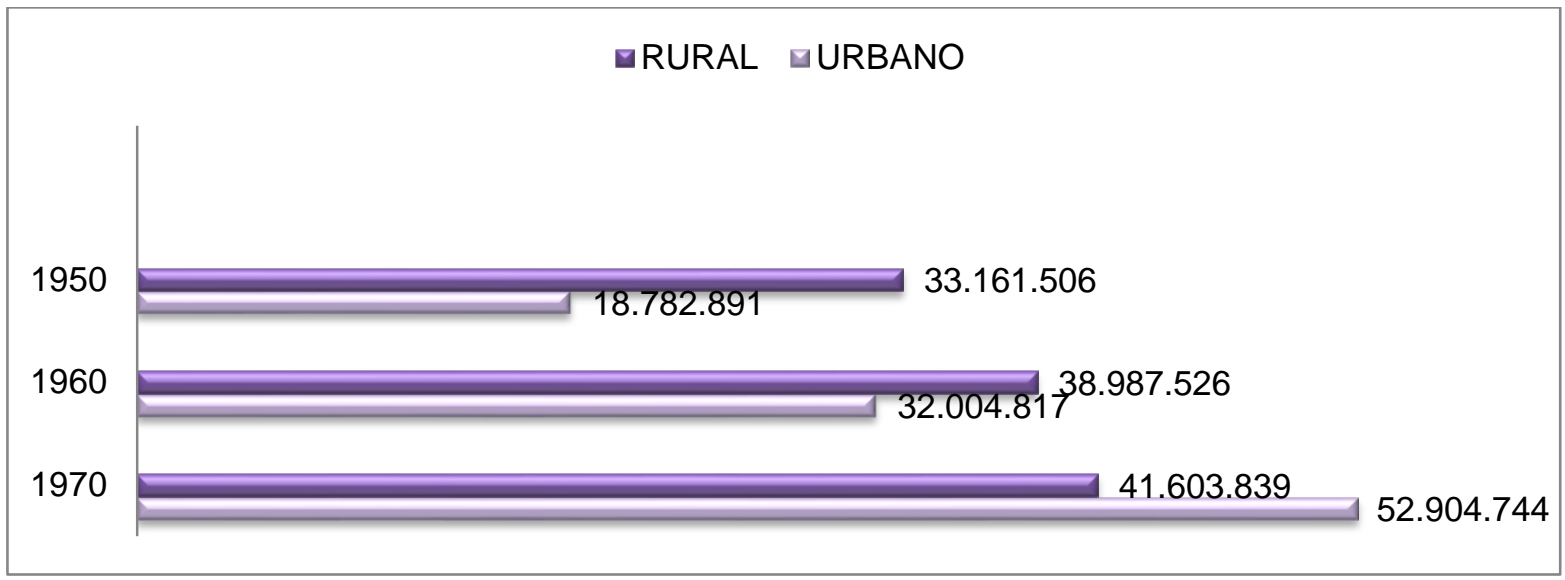

Fonte: Dados do Censo Demográfico - Séries Históricas (IBGE, 2000).

Em termos de contexto nacional, observa-se um crescimento da população urbana durante o período, chegando, na década de 1970, a uma inversão quantitativa na sua distribuição, a população residente na área urbana era maior do que a residente na área rural. No período entre 1950-1970, o crescimento da população rural foi de $25,45 \%$, e da urbana foi de $181,66 \%$, significando que $81,94 \%$ de sua população vivia em regiões urbanas. Essa movimentação da população trouxe uma outra forma de vida para muitos sujeitos e uma outra demanda para os sistemas educacionais brasileiros.

No entanto, o que se identifica como mudança em termos de concentração da população em zonas urbanas no panorama nacional não se aplica ao Estado do Paraná, em particular. O total da população do Estado em 1950 era de 2.115.547 habitantes. Em 
1960, essa quantia salta para 4.296.375 e, em 1970, para 6.997.682 habitantes. Desses totais, a população se distribuía como está demonstrado na Tabela 2.

Tabela 2: Residentes no Paraná nos anos de 1950, 1960 e 1970-área urbana e rural

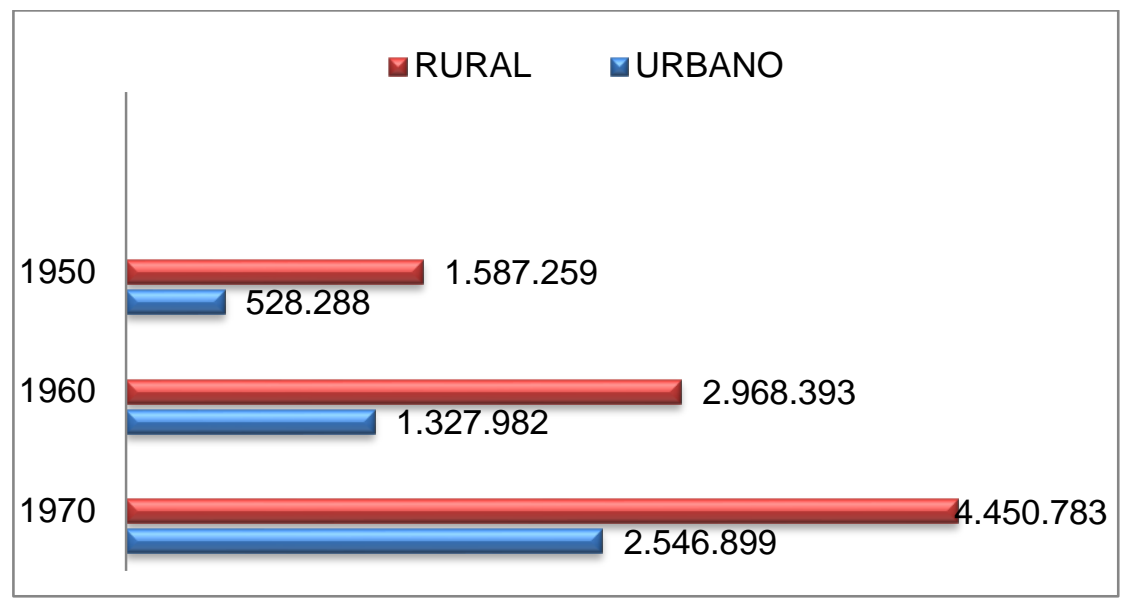

Fonte: Dados do Censo Demográfico - Séries Históricas (IBGE, 2000).

Entre os anos de 1950 e 1970, a predominância no Estado foi de uma concentração da população em áreas rurais. Nos anos de 1950, 75,03\% residia na zona rural e $24,97 \%$ em zona urbana. No ano de $1970,63,60 \%$ da população residia em zona rural e $36,40 \%$ em zona urbana. O crescimento populacional do Estado, nesse período, chegou a 230,8\%. Embora seja possível identificar um crescimento percentual da população em zonas urbanas, a grande maioria ainda residia em zonas rurais. O Paraná, conhecido como o celeiro brasileiro, assistiu a um aumento considerável de sua população, principalmente nas regiões norte, noroeste, oeste e sudoeste, desde os anos de 1930.

A produção agrícola foi uma das grandes responsáveis pelo desenvolvimento do Estado e pela sua ocupação territorial, gerando grande movimento migratório e o fortalecimento da economia paranaense. O estímulo econômico para essa colonização baseou-se na facilidade de aquisição e pagamento de propriedades rurais. A principal empresa colonizadora que atuou no norte do Paraná foi a Companhia de Terras Norte do Paraná que, posteriormente, passou a denominar-se Companhia Melhoramentos Norte do Paraná (BAREIRO, 2007). Assim, a iniciativa de colonização dessas regiões provocou um grande movimento migratório no Estado. Atraídos pela propaganda de sua produtividade, famílias encontraram nessas terras um lugar fértil para a produção agrícola, como foi o caso do cultivo do café, "o cultivo desse produto, presente no Estado desde a primeira República, sustentou a sua economia até a década de 1960, período em que se deu início à diversificação das atividades agrícolas e à intensificação do processo de industrialização" (AKSENEN; MIGUEL, 2017, p. 802).

A particularidade do Paraná, que vivia o impacto do influxo do maior movimento migratório interno do período, pode ser percebida na mensagem apresentada pelo governador Bento Munhoz da Rocha Netto à Assembleia Legislativa do Estado, por ocasião da abertura da sessão legislativa de 1951. Assim se pronuncia o governador: 
Não há, em todo o Brasil, oportunidade melhor que a hora vivida pelo Paraná em suas zonas rurais, para o início dessa assistência. Ao contrário do que acontece nas maiores áreas nacionais, é insignificante no Paraná o êxodo das populações para as cidades. E o movimento migratório interno, que há tempos se processa no país, talvez o maior que a história nacional registra, está povoando intensamente as nossas melhores terras de lavoura. Os contingentes humanos que procuram ininterruptamente o norte e o noroeste do Estado, a maior faixa contínua de terras férteis no Brasil, e as correntes imigratórias que, oriundas do extremo sul, procuram o sudoeste e oeste paranaense, garantem uma prosperidade sem par ao nosso Estado. O Paraná possui, desde 1920, o maior crescimento demográfico do Brasil, está sendo intensamente povoado e trabalhado. Mas essa expansão não se faz sem os dramas do homem rural. É necessário que o poder público venha assisti-lo e, aqui, o pode fazer em condições melhores que na maioria dos Estados brasileiros, evitando-se a formação de problemas complexos no futuro. (PARANÁ, 1951, p. 6)

Impulsionados pelas possibilidades de trabalho e por melhores condições de vida, muitos sujeitos deslocaram-se para o interior paranaense, para se fixarem na área rural. Essa questão migratória resultou na geração de possibilidades para se estruturar a vida nesses lugares. A criação de escolas se tornou um imperativo, tendo em vista o maior número de crianças em idade escolar e que necessitavam de escolarização. Assim, a expansão do ensino primário rural é correlata ao processo de interiorização e colonização do Estado (FURTADO, SCHELBAUER E SÁ, 2015).

A escolarização das crianças nesse período acompanha o panorama de dificuldades encontradas em outros estados, assim como o que é possível observar no contexto nacional mais geral. Na Tabela 3, podemos verificar esses dados distribuídos por regiões de domicílio ${ }^{1}$.

Tabela 3: Presentes com 10 anos e mais no Brasil que não sabiam ler e escrever no ano de 1950 quadro geral, urbano, suburbano e rural ${ }^{2}$

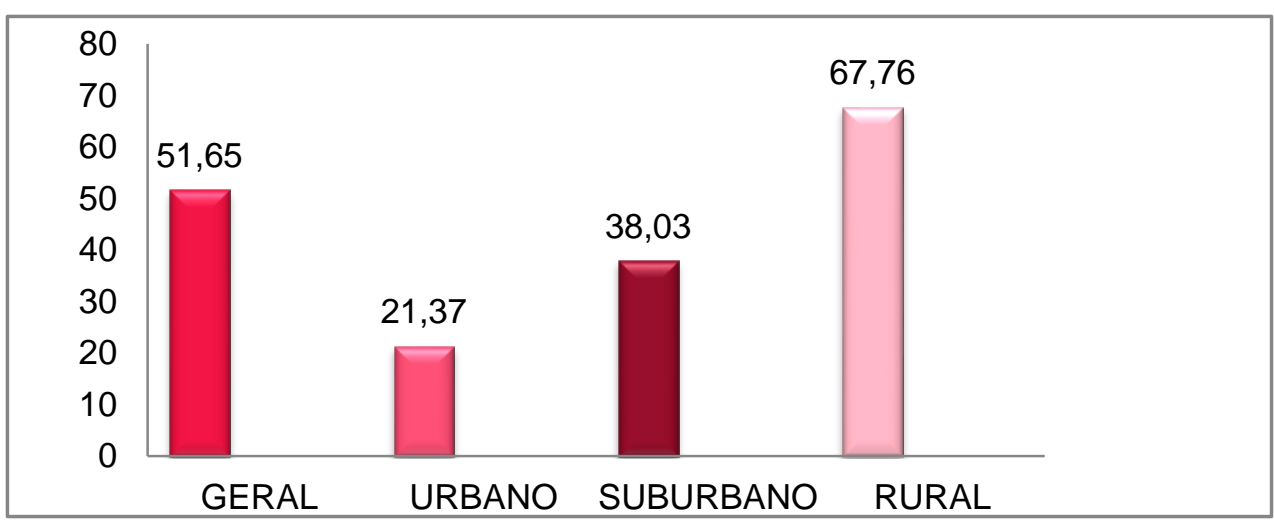

Fonte: Anuário Estatístico Brasileiro (IBGE, 1955).

A diminuição dos índices de analfabetismo foi a grande preocupação de boa parte do período republicano no Brasil. Nos anos de 1900, a taxa de analfabetismo

\footnotetext{
1 De acordo com informações do Anuário Estatístico do Brasil, a população é classificada pela localização do domicílio, que poderia ser em áreas urbanas suburbanas e rurais. O suburbano é entendido como um prolongamento do urbano e das vilas. O rural, como o que está fora do urbano e das vilas.

${ }^{2}$ Esses percentuais são formados tomando como base o total de pessoas que não sabem ler e escrever
} 
acima de 10 anos chegava a 65,3\% (INEP, 2003). Na década de 1950, esse percentual baixou para 51,65\%. Sem entrar na discussão do que marcava a linha divisória entre o que era um analfabeto e o que era um sujeito alfabetizado, nosso objetivo é evidenciar o esforço despendido para retirar o Brasil da condição de país de analfabetos, criando escolas e vagas, assim como estabelecendo políticas públicas que favorecessem a efetivação desse projeto.

No caso do Estado do Paraná, essa distribuição se apresenta da seguinte forma:

Tabela 4: Presentes com 10 anos e mais no Paraná que não sabem ler e escrever no ano de 1950 quadro geral, quadro rural, quadro urbano e quadro suburbano

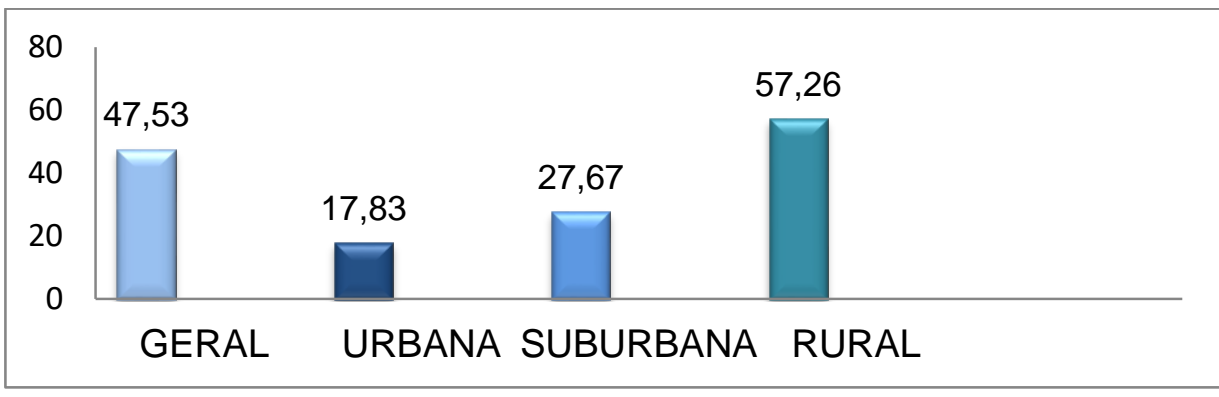

Fonte: Dados do Anuário Estatístico Brasileiro (IBGE, 1955)

Pelos dados, observa-se que 47,53\% da população paranaense acima de 10 anos não sabia ler e escrever. Se compararmos com os dados gerais do país, que era de 51,65\% nesse período, o Paraná apresentava um maior índice de alfabetização, de aproximadamente 4,2\%, em relação à federação, embora os dados fossem alarmantes.

As dificuldades de acesso e permanência das crianças na escola resultam em índices mais elevados de analfabetismo na região rural. Por outro lado, os adultos analfabetos encontravam mais estímulos e facilidades em regiões urbanas para se alfabetizarem. O domínio da leitura e da escrita era condição necessária para sobreviver e se sentir incluído na cidade. A vida rural pouco mecanizada exige um outro tipo de conhecimento, muito mais próximo de um saber fazer transmitido de pai para filho. Os dados estatísticos evidenciam um maior índice de analfabetismo nas zonas rurais. No Brasil, o percentual de analfabetos em zonas rurais era de 67,76 \% e, no Paraná, este índice era de 57,26\%, ficando abaixo da média nacional.

Em termos percentuais, os dados estatísticos evidenciam um crescimento no número de pessoas alfabetizadas no Brasil (IBGE, 1955; 1965; 1978), isso leva a refletir que o número de escolas e de vagas foi se ampliando ao longo dessas décadas. Contudo, isso não significou que a meta de uma escola pública estendida a todos havia se efetivado. Em 1951, o Governador paranaense Bento Munhoz da Rocha Netto expõe que existiria uma deficiência no atendimento escolar. Segundo ele, "só um terço da população escolar do Paraná está sendo atendida, permanecendo cerca de 300.000 crianças sem assistência educacional. $O$ déficit se manifesta mais grave nas regiões norte e oeste do Estado" (PARANÁ, 1951, p. 112).

$\mathrm{O}$ déficit no atendimento às crianças em idade escolar tem uma permanência ao longo dos anos. Este dado deve ser pensado no contexto de um estado que via sua população aumentando progressivamente em decorrência do fluxo migratório. No ano de 1964, segundo o governador Ney Braga, com a realização do Censo Escolar, 
verificava-se uma população em idade escolar, na faixa etária de 7 a 14 anos, de mais de um milhão de crianças, e que, ainda, haveria um déficit no número de matrículas. Essa dificuldade seria mais acentuada nas zonas rurais (PARANÁ, 1965).

Os estudos revelam que, no início dos anos 1960, no Brasil, a rede de ensino primária não atendia a $60 \%$ das crianças em idade escolar. Além disso, das crianças matriculadas na primeira série, apenas $18 \%$ conseguiam concluir o curso. Esse fator era mais acentuado nas áreas rurais, que contavam com pouca infraestrutura e, muitas vezes, com a falta de professores, em decorrência da localidade (SOUZA, 2008). No Estado do Paraná, no final dos anos de 1960, do total de crianças ingressantes na primeira série, $62,8 \%$ concluíam o curso, contudo apenas $24,6 \%$ ingressavam na $4^{\mathrm{a}}$ série. Se compararmos as crianças matriculadas na capital com as matriculadas no interior, observa-se que, na capital, $66,8 \%$ concluíam a primeira série para $43 \%$ no interior. Na capital, em torno de $65 \%$ delas ingressavam na $4^{\mathrm{a}}$ série, para $22 \%$ no interior (PARANÁ, 1968, p. 92).

Das crianças matriculadas na primeira série, $94 \%$ residiam no interior paranaense, local marcado pela existência de diferentes tipos de instituições escolares.

\section{A organização do ensino primário e suas instituições}

O Período de que ora nos ocupamos foi regido pelas chamadas Leis Orgânicas do Ensino, da União, que procuraram padronizar o sistema nacional de educação, antes da aprovação da Lei de Diretrizes e Bases da Educação, com vista às demandas econômicas e sociais do país. O Decreto-Lei n.8.529, de 02/01/1946 - Lei Orgânica do Ensino Primário, norteou o Estado do Paraná na elaboração de sua Lei Orgânica que reorganizou o ensino público primário por meio do Decreto-Lei n.435, de 26 de janeiro de 1946. Este Decreto estabeleceu normas sobre o funcionamento do ensino primário no Paraná, além de orientações pedagógicas, organizacionais e medidas auxiliares.

Com relação aos tipos de estabelecimentos existentes, o Decreto-Lei $\mathrm{n}^{\circ}$ 8.529, de 02 de janeiro de 1946, da União, estabelece:

Art. 28. Serão assim designados os estabelecimentos de ensino primário mantidos pelos poderes públicos:

I. Escola isolada (E.I.), quando possua uma só turma de alunos, entregue a um só docente.

II. Escolas reunidas (E.R.), quando houver de duas a quatro turmas de alunos, e número correspondente de professores.

III. Grupo escolar (G.E.), quando possua cinco ou mais turmas de alunos, e número igual ou superior de docentes.

IV. Escola supletiva (E.S.), quando ministre ensino supletivo, qualquer que seja o número de turmas de alunos e de professores (BRASIL, 1946).

A Lei Orgânica do Ensino primário da União disciplinou e estabeleceu uma organicidade para o uso das nomenclaturas das instituições e estabeleceu critérios para a sua adoção. A historiografia da educação das primeiras décadas do século XX, de diferentes Estados da Federação, registra que, além dos grupos escolares e escolas isoladas, há instituições denominadas de escolas rudimentares, promíscuas, ambulantes, 
noturnas, preliminares e casas escolares. Com relação a essas diferentes denominações, compreende-se que "envolveu aspectos administrativos, organizacionais e pedagógicos incluindo diferentes propostas de ensino, de programas, de condições materiais e de tempo de duração do curso primário" (ARAÚJO; VALDEMARIN; SOUZA, 2015, p. 34). As referências às escolas existentes na área rural paranaense são as de escolas isoladas rurais, grupos escolares rurais e escolas de trabalhadores rurais e pescadores (SCHELBAUER, 2014).

A legislação, ao regulamentar os tipos institucionais, imprime uma maior objetividade e torna operacional a sua utilização. A existência de uma pluralidade de terminologias, como atesta a historiografia das primeiras décadas da República, pode revelar o encontro de temporalidades diversas no plano da mudança e das continuidades no campo da organização da instituição escolar. Modelos mais modernos e inovadores convivem com modelos mais antigos e que, às vezes, guardam reminiscências de outros tempos, mas que esquecem a conjuntura de seu próprio estabelecimento, pois carregam, também, as rupturas da novidade e que as transformaram em algo diferente do que eram.

Interessa-nos, aqui, evidenciar, até onde os materiais analisados permitem, as características da organização do trabalho na escola isolada. Como seu próprio nome diz, ela se caracterizou por um isolamento administrativo e pedagógico. Esta escola se organizava com alunos de séries, de faixa etária e de conhecimentos diferentes, reunidos em uma mesma sala e sob o comando de um só professor. O modelo firmou suas raízes e foi responsável pela educação escolar da população em diferentes regiões do Brasil (ARAÚJO; VALDEMARIN; SOUZA, 2015; ROSSI, 2003; 2017a). Com seu modo próprio de organização, as escolas isoladas também fizeram parte do contexto educacional paranaense, estando localizadas, em grande parte, em áreas rurais, em vilas e pequenos núcleos urbanos

A escola isolada diferia do grupo escolar, pois tratava-se de um outro espaço físico e possuía uma organização do trabalho bastante particular, como a literatura especializada tem destacado. No entanto, é preciso considerar, como assevera Chartier (1990), que as objetivações constroem formas originais ao realizarem o uso de determinada coisa. Assim, o que se propõe é um olhar mais sensível à cultura da escola isolada, para aquilo que ela construiu de original e de propriamente seu ao organizar o modelo de ensino seriado e graduado.

Em entrevistas realizadas com professoras de escolas isoladas das décadas de 1950 e 1960, foi possível verificar que as salas de aula, embora heterogêneas e multisseriadas, organizavam-se internamente por meio da lógica da homogeneidade. Organizavam-se os alunos por grupos separados, sendo acomodada uma série em cada um deles. Seguindo esta lógica, as professoras dividiam o quadro negro em tantos espaços quantas fossem as séries, sendo cada um deles destinado a uma delas. Ou, ainda, utilizavam-se de materiais e estratégias de ensino diferentes e correspondentes a cada uma das séries. Dessa forma, as professoras se dirigiam, em momentos alternados, a grupos de alunos organizados por meio da classificação em série. Identifica-se a predominância de um ensino simultâneo, realizado para cada um dos grupos em específico. Vejamos o que dizem três entrevistadas:

- Eu fazia assim, no fundo da classe eu arrumava o quarto ano, mas no começo da classe eu arrumava o segundo ano, então quando assim, eu dava tarefa, dava uma explicação pro quarto ano e pedia alguma coisa pra eles fazer e eu ia pro segundo ano ensina, aquelas meninas mais espertas que 
acabava, vinham me ajuda ensinar o $2^{\circ}$ ano. E foi uma coisa boa, com a colaboração. (DEUS, 2015, p.120).

- É um pouco complicado, porque a gente tem que trabalhar com 2 turmas ...! Tinha que passar, passava às vezes tarefa no quadro pra uma turma e enquanto aqueles iam copiando, fazendo os exercícios a gente passava, ia do outro lado atender a outra turma. (FERREIA, 2018, p.180)

Quando eu passei do $1^{\circ}$ pro $2^{\circ}$ e o $3^{\circ}$ ano, quando eu já estava no $3^{\circ}$ ano era muito aluno, não cabia mais ..., nessas salas. Aí o que que ela fez? Como não tinha nenhuma outra professora pra trabalhar, ela dividiu assim: um dia trabalhava o $1^{\circ}$ e o $2^{\circ}$ ano, no outro dia o $3^{\circ}$ ano. Então assim, o $3^{\circ}$ ano estudava 2 vezes na semana, e o $2^{\circ}$ e o $1^{\circ}$ três vezes na semana, mas a gente estudou e aprendeu bem. (HERA, 2018, p.191)

Observa-se que o agrupamento em série dos alunos ocorria no espaço interno da sala de aula ou na organização do horário semanal da escola. Este agrupamento objetivava organizar o grupo de alunos no nível de aprendizagem correspondente à graduação das etapas de conhecimento, tornando possível a simultaneidade de exposição de conteúdos e de execução de tarefas.

Foi durante a República que o modelo seriado e graduado se consolidou no ensino primário. Esse modelo escolar foi utilizado desde o século XIX em países da Europa e nos Estados Unidos, no processo de democratização da educação e implantação da educação elementar para todos. Contudo, para que a organização seriada ocorresse, foram necessárias outras mudanças no campo da concepção e das práticas educacionais. A literatura tem destacado elementos essenciais que permitiram o seu desenvolvimento, dentre eles, o uso do método simultâneo de ensino; a utilização de materiais didáticos; a organização dos conteúdos em programas, com a definição de tempo para sua realização; a existência de um mobiliário específico e de espaços construídos para fins educacionais; a certificação dos estudos e a formação de profissionais específicos (ROSSI, 2003,2017b; SAVIANI, et al, 2017; SOUZA, 2014;).

O desenvolvimento e aprimoramento destas novidades possuem uma história. Contudo, todos elas se articularam para a constituição de um modelo de escola fundada numa forma de organização do trabalho. É possível compreender que a organização do trabalho escolar se estruturou a partir de dois elementos: o tempo e o espaço. A organização temporal criou padrões para o ensino e para a aprendizagem, promovendo uma classificação, divisão e padronização, tanto nos grupos escolares, como nas escolas isoladas. A classificação e a seriação se construíram em torno de uma temporalidade compactuada, definida em lei e seguida por todos os tipos de escola. Os espaços físicos destas instituições são diferentes e eles definem as particularidades na organização do trabalho. O grupo escolar organiza o trabalho na forma mais elevada da divisão do trabalho e nisso reside a sua principal modernidade e diferença em relação ao trabalho da escola isolada. No entanto, a organização do espaço para o ensino segue a mesma concepção: a composição de grupos mais ou menos homogêneos que executavam uma mesma atividade transmitida de forma simultânea. No grupo escolar, identifica-se a existência da classe, legitimada por um espaço físico exclusivo, a sala. $\mathrm{Na}$ escola isolada, em sua maioria, não existia a materialidade da separação do espaço em mais de uma sala, mas a divisão na organização do trabalho ocorria por meio da organização de grupos de alunos que correspondiam a um mesmo nível de aprendizado. Assim, o princípio da seriação e da classificação para o ensino e aprendizagem pode ser identificado em ambas. 
Neste aspecto, é bastante revelador o depoimento de professoras que vivenciaram a transformação de uma escola isolada para grupo escolar. Quando questionadas sobre a mudança, assim se manifestaram:

\begin{abstract}
__... Não achei que mudou muita coisa não...Eu acho que continuou o mesmo, não tenho lembrança que mudou muita coisa não. Talvez mudou assim que a gente tinha mais reunião assim com os professores, com a diretora né, isso acho que mudou. A gente tinha mais reuniões, reuniões mais seguidas, é. Mais orientação também daí né, isso nesse ponto mudou. (FERREIA, 2018, p.184)

- ... você quer dizer, por exemplo, antes era tudo multisseriado junto e depois... ah... foi muito bom, muito bom. ... Não que fosse muito difícil dar aula junto, mas ... foi bem melhor .... Porque a professora mesmo tinha mais tempo pra ensinar aquela turma ... E ... eu acho assim que a mudança ajudou muito, sempre pra melhor ... (HERA, 2018, p.192)
\end{abstract}

Pelos depoimentos, o elemento diferenciador identificado pelas professoras é o de gestão: a gestão institucional e a gestão de sala de aula. Os grupos escolares complexificaram a dinâmica institucional, por um lado, e otimizaram o modelo de ensino seriado e graduado. Contudo, para a criação dos grupos, exigia-se uma certa concentração populacional, pois requeria a existência mínima de cinco salas de aula. No Paraná, no período em estudo, a maioria da população vivia nas regiões rurais e suburbanas, o que significou que o ensino elementar chegou a esses sujeitos, fundamentalmente, por meio das escolas isoladas.

Vale destacar que a promulgação da primeira Lei de Diretrizes e Bases da Educação Nacional (LDBEN), em 1961, não alterou os tipos de instituições estabelecidos na Lei de 1946. Durante os anos de 1960, os tipos de instituições escolares continuaram a atender as especificidades geográficas e de distribuição da densidade populacional do país, permitindo identificar que o modelo graduado de ensino se organizou em espaços institucionais diversos, criando características próprias para cada um deles.

\title{
CONSIDERAÇÕES FINAIS
}

Fomos um país de vida predominantemente agrária até pouco tempo. A extensão da educação pública a todos, no Brasil, atendeu a desafios dessa particularidade e da natureza de sua extensão continental. No Paraná, a difusão da escola isolada e de sua forma de organização do trabalho parece ser um exemplo relevante dos tipos de escolas existentes em meados do século XX e que foram responsáveis por grande parte da generalização da instrução primária.

Embora os grupos escolares, considerados modelos de modernidade e de boas práticas pedagógicas, fizessem parte do desejo e dos discursos da educação de meados do século XX, a interiorização da educação ocorreu, fundamentalmente, por meio das escolas isoladas e reunidas. Os grupos escolares organizaram os alunos por séries, cada qual em uma sala específica, denominada de classes, e aplicavam o método simultâneo de ensino. A existência de acompanhamento pedagógico em seu cotidiano, que auxiliava no desenvolvimento dos programas de ensino, assim como a divisão do trabalho em seu interior, configurou-os como melhor modelo de organização institucional e de trabalho. No entanto, esse modelo não era funcional para todos os locais e regiões de um país agrário e de proporções continentais. 
O caminho não foi único. No Brasil, observamos que, ao mesmo tempo em que houve a construção dos grupos escolares, houve a proliferação das escolas isoladas e reunidas durante a primeira metade do século XX (ROSSI, 2003) e, no Paraná, em particular, essa realidade avança as décadas de 1960 e 1970.

Assim, se a chamada escola graduada mobilizou o ocidente em torno de seus propósitos e das mudanças estruturais que a novidade impunha, em muitas regiões, como no interior paranaense, configurou-se um modelo de organização de escola que conjugou muitas das novidades do campo educacional às condições de um país agrário, com uma população dispersa em seu imenso território, com dificuldades econômicas e com escassez de qualificação profissional. A escola isolada, ao contar com apenas uma sala de aula multisseriada, não possuía, em sua materialidade, os sinais expressos de uma mentalidade que construiu divisões e criou padrões. No entanto, ao adentrar no terreno das práticas, os mesmos enquadramentos podem ser observados. No interior da sala de aula, a organização do trabalho seguia a classificação dos alunos, divididos e organizados em pequenos grupos de níveis mais ou menos homogêneos de aprendizado, permitindo ao professor o desenvolvimento de um ensino simultâneo a cada um dos grupos.

Assim, identifica-se que o trabalho docente se organiza a partir da mesma lógica de graduação e seriação. Em depoimento, professoras que atuaram junto a uma instituição que mudou de escola isolada para grupo escolar entendem que a maior mudança estava relacionada à gestão de sala de aula e da instituição.

Assim, a democratização do ensino exigiu percorrer diferentes caminhos e impôs a utilização de tipos de instituições diferentes. Estes espaços físicos e suas culturas estiveram adaptadas ao seu lugar, deixando ver que as apropriações de ideias e práticas do modelo de organização de ensino graduado percorreu diversas particularidades.

\section{REFERÊNCIAS}

ARAÚJO, José Carlos Souza Araújo; VALDEMARIN, Vera Teresa; SOUZA, Rosa Fátima de. A contribuição da pesquisa em perspectiva comparada para a escrita da História da Escola Primária no Brasil: notas de um balanço crítico. In: SOUZA, Rosa Fátima de; PINHEIRO, Antônio Carlos Ferreira; LOPES, Antônio de Pádua Carvalho. História da Escola Primária no Brasil: investigações em perspectiva comparada em âmbito nacional. Aracaju: EDISE, 2015. p. 27-45.

AKSENEN, Elisângela Zarpelon; MIGUEL, Maria Elisabeth Blanck. A Educação Rural no Paraná no início do século XX: a voz dos documentos oficiais. In: Congresso Brasileiro de História da Educação, 2017. Anais... João Pessoa: UFP, 2017. p. 799-814.

BAREIRO, Edson. Políticas educacionais e escolas rurais no Paraná - 1930-2005. 107 f. Dissertação (Mestrado em Educação para a Ciência e o Ensino de Matemática) Universidade Estadual de Maringá, Maringá, 2007.

BRASIL. Instituto Brasileiro de Geografia e Estatística. Anuário Estatístico do Brasil. Conselho Nacional de Estatística, 1955. Disponível em: <https://biblioteca.ibge.gov. br/visualizacao/periodicos/20/aeb_1955.pdf>. Acesso em: 6 jun. 2017. 
. Instituto Brasileiro de Geografia e Estatística. Anuário Estatístico do Brasil.

Conselho Nacional de Estatística, 1965. Disponível em: <https://biblioteca.ibge.gov.br/visualizacao/periodicos/20/aeb_1965.pdf >. Acesso em: 6 jun. 2017.

. Instituto Brasileiro de Geografia e Estatística. Anuário Estatístico do Brasil. Conselho Nacional de Estatística, 1978. Disponível em: <https://biblioteca.ibge.gov.br/visualizacao/periodicos/20/aeb_1978.pdf>. Acesso em: 6 jun. 2017.

Séries . Instituto Brasileiro de Geografia e Estatística. 2000. Censo Demográfico. Séries Históricas - População (1950-2010). Disponível em: <https://www.ibge.gov.br/estatisticas-novoportal/sociais/educacao/9663censodemografico-2000.html?edicao $=9859 \& \mathrm{t}=$ =series-historicas $>$. Acesso em: 16 nov.2017.

Instituto Nacional de Estudos e Pesquisas Educacionais Anísio Teixeira (INEP). Mapa de Analfabetismo no Brasil. 2003. Disponível em $<$ http://portal.inep.gov.br/documents/186968/485745/Mapa+do+analfabetismo+no+Bra sil/a53ac9eec0c0-4727-b216-035c65c45e1b?version=1.3>. Acesso em: 5 ago. 2017.

Lei de Diretrizes e Bases da Educação Nacional. Lei no 4.024 de 20 de dezembro de 1961. Brasília, DF: MEC, 1961. Disponível em: <http://www2.camara.leg.br/legin/fed/lei/1960-1969/lei-4024-20-dezembro-1961353722-publicacaooriginal-1-pl.html>. Acesso em: 20 jan. 2017.

Legislação Informatizada. Decreto-Lei $n^{o}$. 8.529, de 2 de janeiro de $1946-$ Publicação Original. Lei Orgânica do Ensino Primário. Brasília, DF: Lei Orgânica do Ensino Primário, 1946b.

CERTEAU, Michel de. A invenção do cotidiano: artes de fazer. 21 ed. Petrópolis, RJ: Vozes, 1998.

CHARTIER, Roger. A história cultural. Entre práticas e representações. Lisboa: DIFEL, 1990.

BITTAR, Marisa; BITTAR, Mariluce. História da Educação no Brasil: a escola pública no processo de democratização da sociedade. Acta Scientiarum Education, Maringá, v. 34, n. 02, p. 157-168, jul./dez. 2012.

BOBBIO, Norberto. A era dos direitos. Rio de Janeiro: Elsevier, 2004.

DEUS, Orendina Carolina de. Apêndice A. [Entrevista concedida a] Elena Pericin Gomes Cornicelli. História da Educação Rural de Astorga: práticas educativas e 
organização institucional da Escola Rural Água Astorga (1957-1980). 2015. 121 f. Dissertação (Mestrado em Educação) - Universidade Estadual de Maringá, Maringá, 2015.

FERREIA, E. T. S. Apêndice B: entrevista B. [Entrevista concedida a] Jordana Ferreira de Faria. In: FARIA, J. F. A cultura escolar como produto de um lugar: uma escola primária rural do interior paranaense (1950-1970). 2018. 220f. Dissertação (Mestrado em Educação) - Universidade Estadual de Maringá, Maringá, 2018.

FURTADO, Alessandra Cristina; SCHELBAUER, Analete Regina; SÁ, Elizabeth Figueiredo de. Escola Primária Rural: Caminhos percorridos pelos estados de Mato Grosso e Paraná (1930 - 1961). In: SOUZA, Rosa Fátima de; PINHEIRO, Antonio Carlos Ferreira; LOPES, Antônio de Pádua Carvalho. História da Escola Primária no Brasil: investigações em perspectiva comparada em âmbito nacional. Aracaju: EDISE, 2015. p. 103-146.

HERA. Apêndice C: entrevista C. [Entrevista concedida a] Jordana Ferreira de Faria. In: FARIA, J. F. A cultura escolar como produto de um lugar: uma escola primária rural do interior paranaense (1950-1970). 2018. 220f. Dissertação (Mestrado em Educação) Universidade Estadual de Maringá, Maringá, 2018.

PARANÁ. Mensagem apresentada à Assembleia Legislativa do Estado por ocasião da abertura da $1^{\text {a }}$ Sessão Ordinária da $2^{\text {a }}$ Legislatura de 1951, pelo senhor Bento Munhoz da Rocha Netto, Governador do Paraná. Curitiba, 1951. Disponível em:〈http://www.arquivopublico.pr.gov.br/arquivos/File/pdf/Ano_1951_MFN_944.pdf> Acesso em: 9 jun. 2017.

. Mensagem apresentada à Assembleia Legislativa do Estado por ocasião da abertura da $3^{\text {a }}$ Sessão Ordinária da $5^{\text {a }}$ Legislatura de 1965, pelo senhor Ney Aminthas de Barros Braga, Governador do Paraná. Curitiba, 1965. Disponível em:<http://www.arquivopublico.pr.gov.br/arquivos/File/pdf/Mensagem_1965_MFN_16 67.pdf>. Acesso em: 12 nov. 2017.

- Mensagem apresentada à Assembleia Legislativa do Estado por ocasião da abertura da $2^{\text {a }}$ Sessão Ordinária da $6^{\text {a }}$ Legislatura de 1968, pelo senhor Paulo Cruz Pimentel, Governador do Paraná. Curitiba, 1968. Disponível em: $<$ http://www.arquivopublico.pr.gov.br/arquivos/File/pdf/Mensagem_1968_mfn_1662.p df $>$. Acesso em: 12 nov. 2017.

ROSSI, Ednéia Regina. Insuladas tribos: a escola primária e a forma de socialização escolar. São Paulo (1912-1920). 2003.165 f. Tese (Doutorado em História) - Faculdade de Ciências e Letras, Universidade Estadual Paulista, Campus de Assis, 2003. 
Ednéia Regina. Escolas reunidas e grupos escolares: traços da modernidade técnico-científica no ensino elementar (1889-1929). Acta Scientiarum: Human and Social Sciencies, v.39, p.317-325, 2017a.

Ednéia Regina A educação escolar primária na Primeira República (18891929). Séries-Estudos, Campo Grande: MS, v. 22, n. 45, p. 159-171, mai/ago. 2017b.

SAVIANI, Dermeval et al. O legado educacional do século XX no Brasil (livro eletrônico). Campinas, SP: Autores Associados, 2017.

SCHELBAUER, Analete Regina. Da roça para a escola: institucionalização e expansão das escolas primárias rurais no Paraná (1930-1960). História da Educação, Dossiê da Revista de História da Educação do Rio Grande do Sul, Porto Alegre: RS, v. 18, p. 7191, maio/ago. 2014.

SOUZA, Rosa Fátima de. História da organização do trabalho escolar e do currículo no século XX: ensino primário e secundário no Brasil. São Paulo: Cortez, 2008.

SOUZA, Rosa Fátima de. Espaço da Educação e da Civilização: Origens dos Grupos Escolares no Brasil. In: SAVIANI, Dermeval et al. O legado educacional do século XIX no Brasil. 3.ed. Campinas, SP: Autores Associados, 2014. p. 33-79.

VINCENT, Guy; LAHIRE, Bernard; THIN, Daniel. Sobre a história e a teoria da forma escolar. Educação em revista, Belo Horizonte, n. 33, jun/2001.

Recebido em: 09/01/2020

Aprovado em: 05/03/2020 